\title{
Large-scale tissue-specific and temporal gene expression profiles in Pengze crucian carp
}

\author{
Y. Zheng ${ }^{1,2}$, J.Z. Chen', H.P. Wang ${ }^{2}$, M. Li ${ }^{2}$, H.W. Liang ${ }^{3}$, X.W. Bing ${ }^{1}$ and \\ Z.Z. Wang ${ }^{2}$
}

${ }^{1}$ Key Open Laboratory of Ecological Environment and Resources of Inland Fisheries, Freshwater Fisheries Research Center, Chinese Academy of Fishery Sciences; Key Laboratory of Genetic Breeding and Aquaculture Biology of Freshwater Fishes, Scientific Observing and Experimental Station of Fishery Resources and Environment in the Lower Reaches of the Changjiang River, Ministry of Agriculture, Wuxi Fisheries College, Nanjing Agricultural University, Wuxi, China ${ }^{2}$ College of Animal Science and Technology, Northwest A\&F University, Shaanxi Key Laboratory of Molecular Biology for Agriculture, Yangling, Shaanxi, China ${ }^{3}$ Yangtze River Fisheries Research Institute, Chinese Academy of Fishery Sciences,

Wuhan, Hubei, China

Corresponding authors: Y. Zheng / Z.Z. Wang

E-mail: zhengy@ffrc.cn / zzwang@nwsuaf.edu.cn

Genet. Mol. Res. 15 (1): gmr.15017642

Received September 15, 2015

Accepted December 9, 2015

Published March 31, 2016

DOI http://dx.doi.org/10.4238/gmr.15017642

ABSTRACT. In the present study, the tissue-specific and temporal gene expression profiles of four catalogues of gonadal development-related genes (sex differentiation-related, steroid receptor, steroidogenic, and structural genes) were detected in nine tissues and during 11 successive developmental stages in the Pengze crucian carp (Pcc) (a triploid monofemale gynogenic fish). The results showed that these target genes exhibited overlapping distributions in various tissues, with the exception of Pcc-vasa and Pcc-cyp17a1. Gene expression profiling of the developmental stages showed that all of the target genes simultaneously reached peak expression levels at 40 and 48 days post hatching (dph). Both 40 and 48 dph appeared to be two key time points associated with the process of 
Pcc gonadal development. These data will provide a clear understanding of gene expression patterns associated with the gonadal developmentrelated genes of this gynogenic teleost.

Key words: Gene expression; Gonadal development; Gynogenic Pengze crucian carp; Tissue-specific; Temporal

\section{INTRODUCTION}

Pengze crucian carp (Carassius auratus var. Pengze; Pcc) can be activated using heterologous sperm from other fish species without nuclear decondensation via artificial propagation methods. It is a naturally gynogenic species that is composed of all-female individuals, and it was identified as a triploid fish. Studies of diploid fish [e.g., zebrafish, medaka, fathead minnow, black porgy (Acanthopagrus schlegelii, Wu et al., 2010), rainbow trout, and Atlantic salmon] have demonstrated that fish sex differentiation is oriented towards one of the sexes, and it is largely dependent on the levels of endogenous sex steroid hormones (testosterone for $\mathrm{T}$, 11-ketotestosterone for 11-KT, and 17 $\beta$-estradiol for E2). Therefore, a change in the balance of steroid hormones can shift the differentiation pathway. E2 plays a vital role in the complete sex reversal of the proandrous hermaphrodite black porgy (Wu et al., 2010). Moreover, lower E2 and high $\mathrm{T}$ levels could promote testicular differentiation in hermaphroditic groupers (Zhou and Gui, 2010). Recently, additional research indicated that endogenous E2 is more important for fish sex differentiation ( $\mathrm{Li}$ et al., 2013a). The longer life cycle and sexual maturation time for triploid fish, compared to the small diploid fish models, implie important differences in the fluctuation of hormone levels, Vtg synthesis, and gonadal maturation (Jensen et al., 2001).

A positive correlation exists between endogenous E2 and aromatase (cyp19a1a) gene expression in teleosts. Furthermore, some genes associated with sex differentiation are involved in endogenous E2 production and the gene regulation/modulation of aromatase activities. AntiMüllerian hormone (amh), a member of the transforming growth factor $\beta$ family, is produced directly by the ovarian follicles (Rodríguez-Marí et al., 2005). Dosage-sensitive sex reversal, adrenal hypoplasia congenital critical region on the X-chromosome gene 1 (dax1), an unusual member of the nuclear receptor superfamily, is essential for normal testicular development, and it influences male fertility (Li et al., 2013a). Doublesex and mab-3 related transcription factor 1 (dmrt1) is the sex determination gene in reptiles and birds, and its expression was predominantly detected in testes as compared to ovaries (Kobayashi et al., 2008). Forkhead box L2 (fox/2) contains a fork-head DNA-binding domain, and it may play a role in ovarian development and function maintenance (Hale et al., 2011; Raghuveer et al., 2011). Nuclear receptor subfamily 5, group A, member 1d (also called steroidogenic factor $1 \mathrm{~d}, n r 5 a 1 b$ ) helps control gene modulation that is related to the development of gonads (ovaries and testes) and adrenal glands (von Hofsten et al., 2005). SF1 protein controls sexual development in the embryo and at puberty. SRY-box containing gene $9 a$ (sox9a) plays an important role in the growth and development process, especially regarding sex determination in male fish (Rodríguez-Marí et al., 2005; Kobayashi et al., 2008). Vasa (vasa) is an essential gene for germ cell development, which belongs to the DEAD-box family.

Until recently, two estrogen receptors (ERs) were found in teleosts [ER $\alpha$ (encoded by esr1) and ER $\beta$ (encoded by esr2)], which play vital roles in the fish reproductive system via estrogen signaling pathways (Segner et al., 2013). The androgen receptor (AR, ar), a member 
of the steroid receptor superfamily, is activated by binding to androgenic hormones, testosterone, and dihydrotestosterone. Among the biochemical pathways in the process of steroidogenesis, steroidogenic acute regulator protein (star) takes charge of the regulatory step during acute steroid production for the transfer of cholesterol into pregnenolone across the mitochondrial membrane, which is mediated by the cytochrome P450-mediated side-chain cleavage enzyme (P450scc, cyp11a1). 3 $\beta$-hydroxysteroid dehydrogenase (3bhsd) is a key enzyme that catalyzes the synthesis of potent steroid hormones (Arukwe et al., 2008). Both hydroxylase and lyase activity of cytochrome $17 \alpha$-hydroxylase/17, 20-lyase 1 (cyp17a1) are required for the synthesis of testosterone (Sampath Kumar et al., 2000). Furthermore, 11 $\beta$-hydroxysteroid dehydrogenase 2 (11bhsd2) converts $11 \beta$-hydroxytestosterone to $11-\mathrm{KT}$, and $11-\mathrm{KT}$ is the main androgen found in the majority of fish species.

Structural genes may also play a potent role in gonadal development (Wang and Lou, 2006), and a correlation between elevated vitellogenin (VTG) levels and the presence of intersex gonads exists (Jobling et al., 1998). A series of VTG synthesis, maturation, processing (including possible cleavage into yolk proteins, lipovitellin heavy/light chains, and phosvitin), and the activities of three zona pellucida proteins (ZP1-ZP3, the main components of mature oocyte cells) was demonstrated in a female-specific manner between the embryonic and late gonadal development periods (Modig et al., 2006).

In our previous studies, the cDNAs of four catalogues were isolated, including sexdifferentiation related genes (amh, dax1, and cyp19a1a in Li et al., 2013a; dmrt1 in Zheng et al., 2014), steroid receptor genes (esr1, esr2, and ar in Zheng et al., 2013), steroidogenic genes, and structural genes (Zheng Y, Chen JZ, Bing XW, Yang YP, et al., unpublished results). Gene expression profiles in different genders (Hale et al., 2011), tissues, and developmental stages (Ijiri et al., 2008; Shi et al., 2013) may have dual functions in sex determination and differentiation. The present study detected all four gene catalogues associated with tissue-specific and temporal distributions in Pcc. The results will provide a foundation for further investigations of the molecular mechanisms associated with estrogen signaling and steroidogenesis in Pcc.

\section{MATERIAL AND METHODS}

\section{Animals and sampling}

The eggs of mature gynogenetic Pcc (weight: $450 \mathrm{~g}$ ) were inseminated with the sperm of the red common carp (Cyprinus carpio var. red style, weight: $600 \mathrm{~g}$ ) to activate eggs during artificial propagation experiments. The collection of parental fish, spawning and spermiation, fish culturing in glass tanks, feeding, and management followed the methods of Zheng et al. (2013, 2014). All fish were euthanized before sampling using 0.1\% 2-phenoxyethanol (Sigma-Aldrich, USA). Nine tissues (brain, eye, gill, hepatopancreas, intestine, kidney, muscle, ovary, and spleen) were sampled from one-year-old adult female Pcc (length: $21 \pm 2.1 \mathrm{~cm}$; weight: $226 \pm 23.2 \mathrm{~g}$; $\mathrm{N}=9$ ), and were subsequently used to detect mRNA tissue distribution. RNA samples from 11 developmental stages were collected every four days from 20 until 60 days post hatching (dph) ( $\mathrm{N}=9 \mathrm{fish} / \mathrm{stage}$ ). To investigate tissue-specific and temporal mRNA expression patterns of the target genes, all of the samples were frozen in liquid nitrogen and kept individually in frozen tubes at $-80^{\circ} \mathrm{C}$ until use. Fish were incubated at $24.0^{\circ} \pm 0.5^{\circ} \mathrm{C}$ with a photoperiod of $14 \mathrm{~h}: 10 \mathrm{~h}$ (light:dark) in 125-L glass tanks with dechlorinated tap water. After $5 \mathrm{dph}$, fish larvae were fed Artemia nauplii 
at a rate of $0.1 \%$ body weight per day. During the experimental period, the water conditions were set as follows: $\mathrm{pH}: 7.0 \pm 0.5$ units; dissolved oxygen: $7.21 \pm 0.13 \mathrm{mg} / \mathrm{L}$; total phosphate: $2.19 \pm$ $0.11 \mathrm{mg} / \mathrm{L}$; total nitrogen: $0.54 \pm 0.10 \mathrm{mg} / \mathrm{L}$; ammonia nitrogen: $0.42 \pm 0.06 \mathrm{mg} / \mathrm{L} ; \mathrm{Mg}: 28.45 \pm 0.12$ $\mathrm{mg} / \mathrm{L} ; \mathrm{Ca}: 46.43 \pm 0.27 \mathrm{mg} / \mathrm{L}$. All of the protocols involving the use of animals were in accordance with approved guidelines of the Animal Care and Use Committee of the Northwest A\&F University (Approval No.: 2011ZX08008-002).

\section{RNA isolation and reverse transcription (RT)}

Adult female fish samples at different developmental stages were homogenized in Trizol reagent (Invitrogen, USA), and total RNA was extracted and treated with RNase-free DNase I (Fermentas, Canada) to remove genomic DNA contamination as previously described (Zheng et al., 2013). The quality of total RNA was verified on $1 \%$ agarose gels via visual inspection of $18 \mathrm{~S}$ and $28 \mathrm{~S}$ rRNA bands and by $\mathrm{A}_{260 \mathrm{~nm}} / \mathrm{A}_{280 \mathrm{~nm}}$ ratios measured with a Nanodrop spectrophotometer (Thermo Electron Corporation, USA). Complementary DNAs (cDNAs) were synthesized from $3 \mu \mathrm{g}$ total RNA with M-MLV reverse transcriptase and oligo(dT) ${ }_{18}$ primer in a $20-\mu \mathrm{L}$ final volume.

\section{qRT-PCR and reference gene selecting}

qRT-PCR was performed using a CFX96 thermocycler (Bio-Rad, USA) and a SYBR Premix ExTaq II kit (TaKaRa, Japan). The qRT-PCRs were conducted in a final $25-\mu \mathrm{L}$ volume using 1X SYBR Premix Ex Taq ${ }^{\mathrm{TM}}, 0.4 \mu \mathrm{M}$ each primer, and $2.5 \mu \mathrm{L}$ RT reaction solution. Cycling parameters were as follows: initial denaturation at $95^{\circ} \mathrm{C}$ for $30 \mathrm{~s} ; 40$ cycles of denaturation at $95^{\circ} \mathrm{C}$ for $5 \mathrm{~s}$ and annealing at $60^{\circ} \mathrm{C}$ for $30 \mathrm{~s}$. Each individual sample was run in triplicate. A melting curve analysis was performed at the end of each PCR thermal profile to verify the specificity of each amplicon. Analyses of SYBR green I density and determination of threshold cycle $\left(C_{t}\right)$ values were carried out using the CFX Manager software (Bio-Rad, USA). The efficiency $(E)$ of each PCR was determined based on the slope generated by a 10-fold diluted cDNA series with five dilution points that were measured in triplicate, and the $E=10$ (-1/slope) equation was used. The selection of reference genes was based on the methods of Zheng et al. (2013).

\section{Tissue-specific and temporal distributions of Pcc target genes}

The mRNA tissue-specific and temporal distributions of four catalogue genes were performed using qRT-PCR. Primers for qRT-PCR are shown in Table 1. The qRT-PCR primers for those genes were designed to avoid the amplification of genomic DNA by spanning intron/exon boundaries, and the mRNA amounts were normalized to the most reliable reference gene. The relative mRNA levels in diverse tissues and stages were calculated using the $2^{-\Delta \Delta C t}$ method (Livak and Schmittgen, 2001).

\section{Statistical analyses}

All data are reported as means \pm standard deviation. Data were tested for normality (Kolmogorov-Smirnov test) and homogeneity of variances (Levene's test) prior to any additional analysis. Prior to the analyses, data were log transformed to meet one-way analysis of variance 
(ANOVA) assumptions of normality and variance homoscedasticity when necessary. In data sets where there was a significant difference, a Kruskal-Wallis analysis and the Dunn post hoc test were conducted $(P<0.05$ for significance).

Table 1. Primers for selected reference and gonadal development-related Carassius auratus var. Pengze (Pcc) genes.

\begin{tabular}{|c|c|c|}
\hline qRT Primer & Sequence (5' to $\left.3^{\prime}\right)$ & Length (bp) \\
\hline Pcc-efla-F & TGGAGGTATTGGAACTGTGCC & \multirow{2}{*}{422} \\
\hline Pcc-efla-R & CAGATTTGAGAGCCTTGGGGT & \\
\hline Pcc-tubulin-F & CCAGGGCTGTGTTTGTAGACC & \multirow{2}{*}{144} \\
\hline Pcc-tubulin-R & CAATAGTGTAGTGTCCACGGGC & \\
\hline Pcc-foxl2-F & TTTATTTCAGTCAAAAGTCTCGTC & \multirow{2}{*}{124} \\
\hline Pcc-foxl2-R & CAAAGCCATTGCGTCATC & \\
\hline Pcc- $n r 5 a l b-\mathrm{F}$ & GATAAAACCCAGAGGAAACGCT & \multirow{2}{*}{354} \\
\hline Pcc-nr5alb-R & GCTGGAAGGATGCGAGGA & \\
\hline Pcc-sox $9 a-\mathrm{F}$ & CTGAGGACGGCAGTGAGCA & \multirow{2}{*}{452} \\
\hline Pcc-sox9a-R & GCTCTTGCTCTCCAGGGCT & \\
\hline Pcc-vasa-F & TACAGGACCCAAGGTTGTCTATG & \multirow{2}{*}{234} \\
\hline Pcc-vasa-R & TGTTTCTGGACAGGAGTAGGCT & \\
\hline Pcc-esrl-F & TACGGCATCAGTAAATCGGGT & \multirow{2}{*}{111} \\
\hline Pcc-esrl-R & GTGCTCCATTCCTTTGTTGCTC & \\
\hline Pcc-er alpha2-F & TAGGCAGCCCTCGCATCTT & \multirow{2}{*}{155} \\
\hline Pcc-er alpha2-R & TGCCTGCTGAGAAGATACCACA & \\
\hline Pcc-esr $2 a-\mathrm{F}$ & TATCATTATGGTGTGTGGTCGTG & \multirow{2}{*}{254} \\
\hline Pcc-esr $2 a-\mathrm{R}$ & ATCCTGCCAGAGAATCGTGTC & \\
\hline Pcc-esr $2 b$-F & CACACTCTACGCCGTCTCTGC & \multirow{2}{*}{134} \\
\hline Pcc-esr $2 b$-R & CCCTAACAGCTTTGCATGAGTAA & \\
\hline Pcc-ar-F & ATGGCAGGTTTGATGGAGGG & \multirow{2}{*}{125} \\
\hline Pcc-ar-R & TCCACAAGTGAGGGCTCCATA & \\
\hline Pcc-3bhsd $-\mathrm{F}$ & GAGGAATGGAATCCGCAATG & \multirow{2}{*}{271} \\
\hline Pcc-3bhsd $-\mathrm{R}$ & CAGAAGTGAGAAGGGCAGAACG & \\
\hline Pcc-11bhsd2-F & GTTTGGCATCATACGGGGC & \multirow{2}{*}{322} \\
\hline Pcc-11bhsd2-R & TGGGGTTGAGGAGAGAGGAGT & \\
\hline Pcc-cypllal-F & AGGAGCCCCGAAGGAAAC & \multirow{2}{*}{139} \\
\hline Pcc-cypllal-R & ACGACCCATAGCGTACAGACC & \\
\hline Pcc-cyp17al-F & GGCTGCAGATATTCCCAAATAAAG & \multirow{2}{*}{144} \\
\hline Pcc-cyp17al-R & TCAGAAGTGCGTCCAAGAGGT & \\
\hline Pcc-star-F & CCACATCCGAAGAAGAAGC & \multirow{2}{*}{130} \\
\hline Pcc-star-R & CTGGTTACTGAGGATGCTGAT & \\
\hline Pcc-vtg $B$-F & AGCGCACCCTGAGAGCACTC & \multirow{2}{*}{180} \\
\hline Pcc-vtg $B$-R & AGCCGCCTTCAACATTTCACGT & \\
\hline Pcc-zp2-F & TTCTCTGCACTTAACCTTCAC & \multirow[b]{2}{*}{214} \\
\hline Pcc-zp2-R & CTGCTCACCATCACGCT & \\
\hline
\end{tabular}

\section{RESULTS}

\section{Tissue-specific distributions of sex differentiation-related genes}

The tissue distributions of the sex differentiation-related genes in diverse tissues of oneyear-old adult female Pcc are shown in Figure 1. In general, mRNA expressions of Pcc-fox/2 and Pcc-nr5a1b in the muscle were significantly higher than those in other tissues (Figure 1A). The highest expression of Pcc-nr5a1b transcripts was found in brain and hepatopancreas tissues (Figure 1B). The Pcc-sox9a transcripts in the hepatopancreas, intestine, and kidney tissues were significantly higher than those in spleen (Figure 1C). The detected Pcc-sox9a transcripts in brain, muscle, and ovary tissues were significantly higher than those in eye and gill tissues. Pcc-vasa transcripts were significantly higher in ovary tissues (followed by gill and hepatopancreas tissues) compared to eye, muscle, and spleen tissues. Several tissues, including brain, intestine, and kidney tissues, showed trace expression of Pcc-vasa transcripts (Figure 1D). 

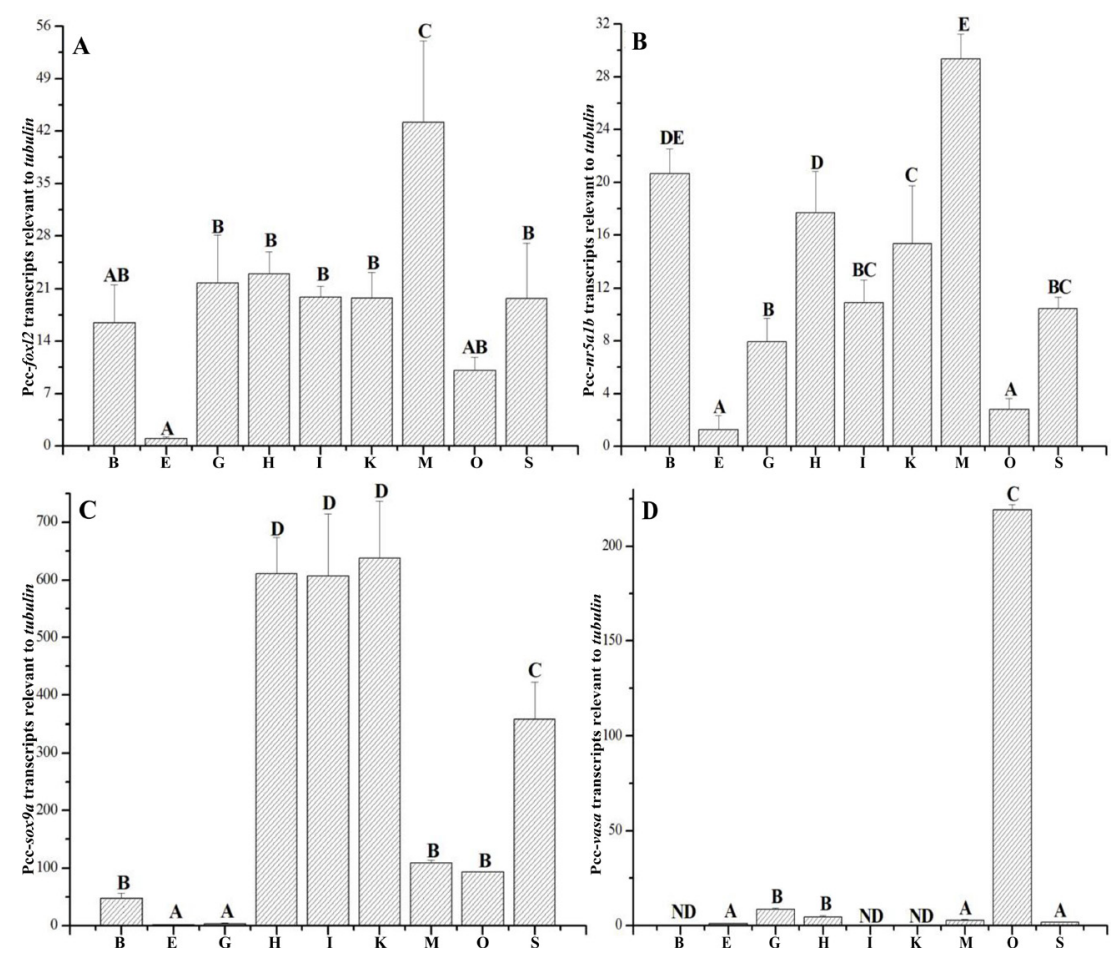

Figure 1. Tissue-specific gene expression profiles of sex differentiation-related genes in nine different tissues. A. Pccfox/2, B. Pcc-nr5a1b, C. Pcc-sox9a, and D. Pcc-vasa. B = brain, E = eye, G: gill, H = hepatopancreas, I = intestine, $\mathrm{K}=$ kidney, $\mathrm{M}=$ muscle, $\mathrm{O}=$ ovary, $\mathrm{S}=$ spleen, and $\mathrm{ND}=$ not detected. The values were calibrated with the internal control tubulin. Each value is reported as means $\pm S D(N=9$ for each value). The different capital letters indicate highly significant differences $(P<0.05)$.

\section{Tissue-specific distributions of steroidogenic genes}

The brain showed higher amounts of Pcc-3bhsd transcripts than other tissues (Figure $2 \mathrm{~A})$. Moreover, the expression levels in spleen and intestine tissues exhibited significantly higher expression compared with other tissues except for both the hepatopancreas and kidney. The expression of Pcc-11bhsd2 transcripts in the muscle and spleen tissues was significantly higher than that found in brain tissues (moderately expressed), and those expressed in gill and intestine tissues were significantly higher than those in eye, hepatopancreas, and kidney tissues (Figure 2B). The expression of Pcc-cyp11a1 transcripts in the hepatopancreas and spleen tissues was significantly higher than that observed in other tissues, with the exception of muscle and ovary tissues (Figure 2C). The Pcc-cyp11a1 transcripts in the remaining tissues, including gill, intestine, and kidney, were significantly higher than those detected in brain tissues (Figure 2C). Pcccyp17a1 was also predominantly expressed in the ovary compared to other tissues. However, several tissues, such as brain, intestine, kidney, muscle, and spleen, showed trace expression of Pcc-cyp17a1 transcripts (Figure 2D). The expression of Pcc-star transcripts in muscle and spleen tissues was significantly higher than that observed in other tissues (Figure 2E). The ranking order of Pcc-star transcripts was hepatopancreas, gill, ovary, kidney, intestine, brain, and eye tissues. 

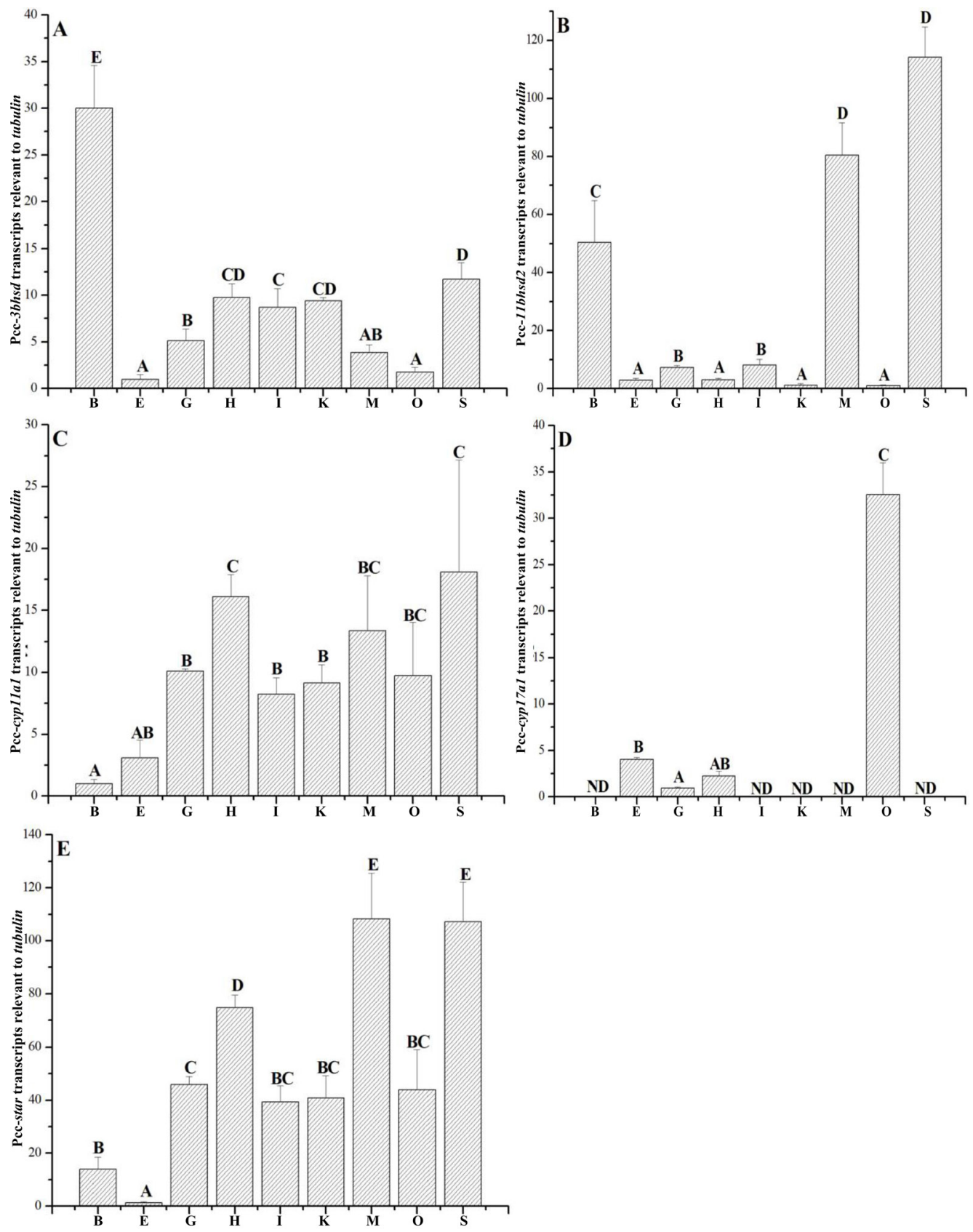

Figure 2. Tissue-specific gene expression profiles of steroidogenic genes in nine different tissues. A. Pcc-3bhsd, B. Pcc-11bhsd, C. Pcc-cyp11a1, D. Pcc-cyp17a1, and E. Pcc-star. The different capital letters indicate highly significant differences $(P<0.05)$. 


\section{Tissue-specific distributions of Pcc-zp2}

The Pcc-zp2 transcripts in the spleen were significantly higher than those in gill, hepatopancreas, intestine, and kidney tissues (Figure 3). Those in brain and ovary tissues were significantly higher than those in eye and muscle tissues.

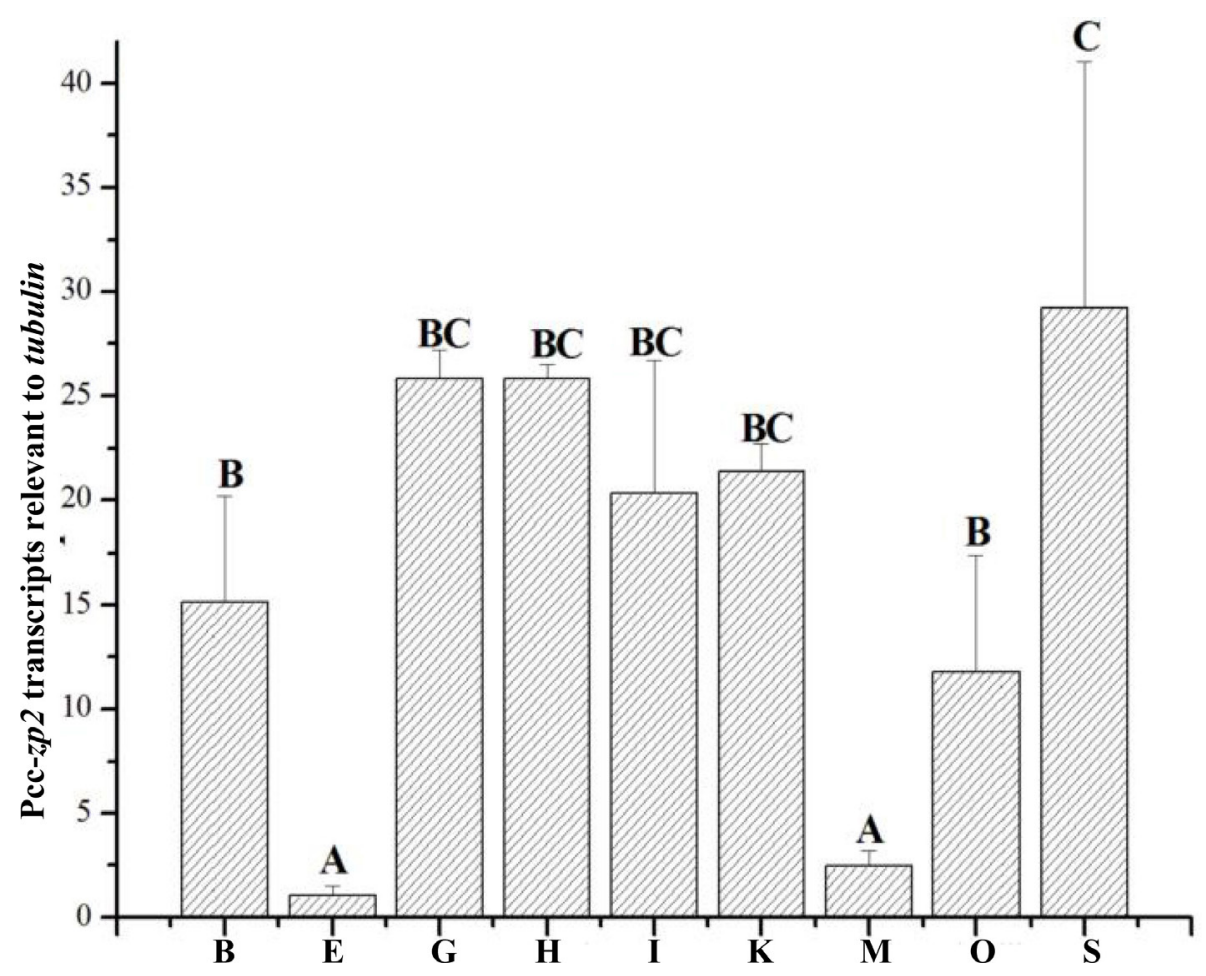

Figure 3. Tissue-specific gene expression profiles of Pcc-zp2 in nine different tissues. The different capital letters indicate highly significant differences $(P<0.05)$.

\section{Temporal distributions of sex differentiation-related genes}

The transcript level of Pcc-fox/2 was lowest at $24 \mathrm{dph}$, and it peaked at $48 \mathrm{dph}$ (Figure 4A). The mRNA level of Pcc-fox/2 persistently increased from 44 to $60 \mathrm{dph}$, and the Pcc-nr5a1b level at 48 dph was significantly higher than that observed at other developmental stages, with the exception of those detected at $44 \mathrm{dph}$ (Figure 4B). The transcript levels of Pcc-sox9a were relatively stable during the developmental stages, with significantly higher expression at 40 and 48 dph $(P<0.05)$ compared to other stages (Figure 4C). The Pcc-sox9a transcripts at 40 dph were significantly higher than other stages, with the exception of those detected at $48 \mathrm{dph}$. The transcript level of Pcc-vasa was lowest at $20 \mathrm{dph}$, and it reached the first and second peaks at 24 and $56 \mathrm{dph}$, respectively (Figure 4D). The Pcc-vasa transcripts at $28 \mathrm{dph}$ were significantly higher than those detected at other stages, with the exception of those at 24 and $56 \mathrm{dph}$. 

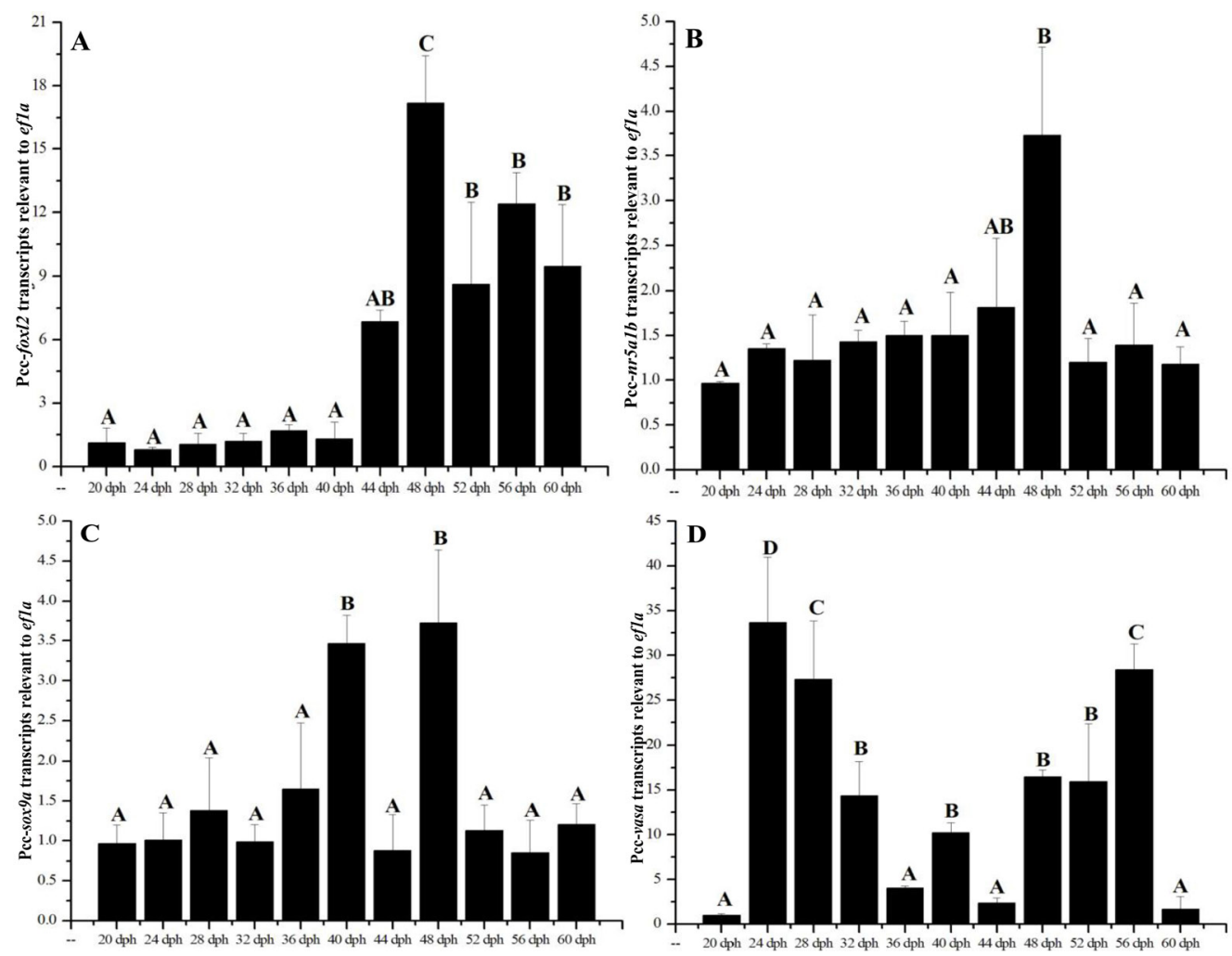

Figure 4. Temporal gene expression profiles of sex differentiation-related genes at 11 different developmental stages. A. Pcc-fox/2, B. Pcc-nr5a1b, C. Pcc-sox9a, and D. Pcc-vasa. The values were calibrated using the internal control ef1a. Transcript abundance is expressed relative to that of the $20 \mathrm{dph}$ stage, and each value is reported as means \pm $\mathrm{SD}(\mathrm{N}=9$ for each value). The different capital letters indicate highly significant differences $(P<0.05)$.

\section{Temporal distributions of steroid receptor genes}

The transcript level of Pcc-esr1 peaked at $48 \mathrm{dph}(\mathrm{P}<0.05$, Figure $5 \mathrm{~A})$, and its expression was significantly higher than that observed at the second stage rank (24, 32, 40, and $52 \mathrm{dph}$ ) and the third stage rank $(20,28,36,44,56$, and $60 \mathrm{dph})$. The highest expression of Pcc-er alpha2 was found at $56 \mathrm{dph}$, and trace expression was detected at 24, 28, and $36 \mathrm{dph}$ (Figure 5B). The Pcc-er alpha2 transcripts at 32 and $40 \mathrm{dph}$ were significantly higher than those at 48 and $60 \mathrm{dph}$, and it was also significantly higher than those observed at 20, 44, and $52 \mathrm{dph}$. The transcript levels of Pcc-esr2a were relatively stable during the developmental stages, with significantly higher expression at 56 and $60 \mathrm{dph}(\mathrm{P}<0.05)$ compared to those at 32, 40, and $48 \mathrm{dph}$ (Figure 5C). Moreover, all of the measurements were significantly higher than those at 20,24, 28, 36, 44, and $52 \mathrm{dph}$. The transcript levels of Pcc-esr $2 b$ showed significantly higher expression at 32 and $40 \mathrm{dph}$ $(P<0.05)$ compared to those observed at 20, 24, 28, and $48 \mathrm{dph}$, and all of the measurements were significantly higher than those at 36, 44, 52, 56, and $60 \mathrm{dph}$ (Figure 5D). The transcript level of Pcc-ar at 40 and 48 dph was significantly higher than those in the second rank (32 and $56 \mathrm{dph}$ ), the third rank $(20,24,28,52$, and $60 \mathrm{dph})$, and the forth rank (36 and $44 \mathrm{dph}$; Figure $5 \mathrm{E}$ ). 

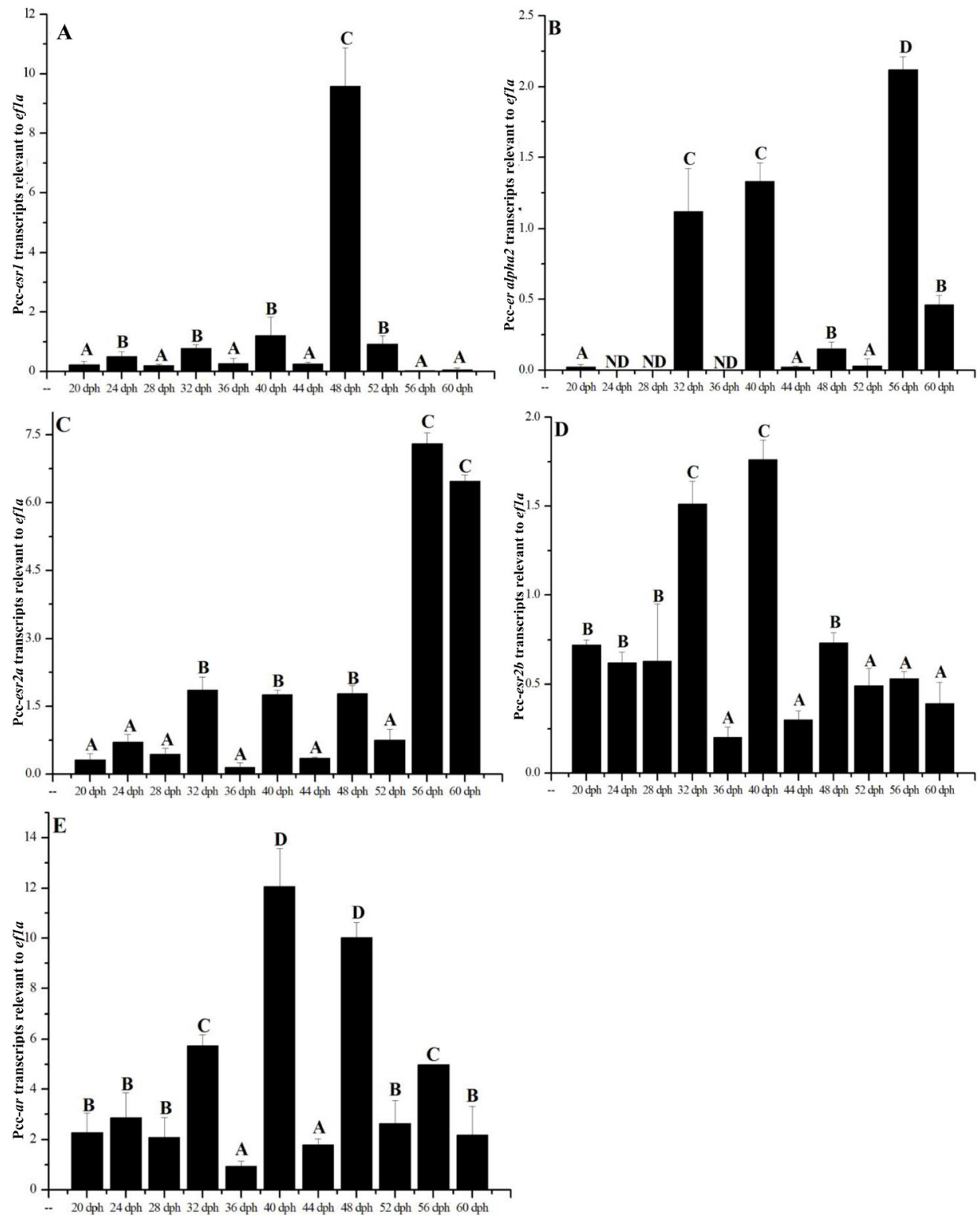

Figure 5. Temporal gene expression profiles of steroid receptor genes at 11 different developmental stages. A. Pcc-esr1, B. Pcc-er alpha2, C. Pcc-esr2a, D. Pcc-esr2b, and E. Pcc-ar. The different capital letters indicate highly significant differences $(P<0.05)$.

\section{Temporal distributions of steroidogenic genes}

The transcript level of Pcc-3bhsd peaked at $20 \mathrm{dph}$, and expression at $48 \mathrm{dph}$ was significantly higher than those observed at other stages, with the exception of 56 dph (Figure 6A). The highest expression of Pcc-11bhsd2 was found at $60 \mathrm{dph}$, and those at $48 \mathrm{dph}$ ranked second. 
Moreover, Pcc-11bhsd2 expression at $40 \mathrm{dph}$ was significantly higher than the remaining stages, with the exception of those at $56 \mathrm{dph}$ (Figure 6B). The Pcc-cyp11a1 transcripts at stages 44 to $60 \mathrm{dph}$ exhibited significantly higher expression than those at stages 24 to $40 \mathrm{dph}$ (Figure 6C). The transcript levels of Pcc-cyp17a1 were relatively stable during the developmental stages, with significantly higher expression at 48 and $60 \mathrm{dph}(P<0.05)$ (Figure 6D). The transcript level of Pccstar exhibited significantly higher expression at stages 48 to $60 \mathrm{dph}$, and the levels peaked at 60 $\mathrm{dph}$. Moreover, Pcc-star expression was significantly higher than levels observed at other stages, with the exception of 20 and $44 \mathrm{dph}$ (Figure 6E).
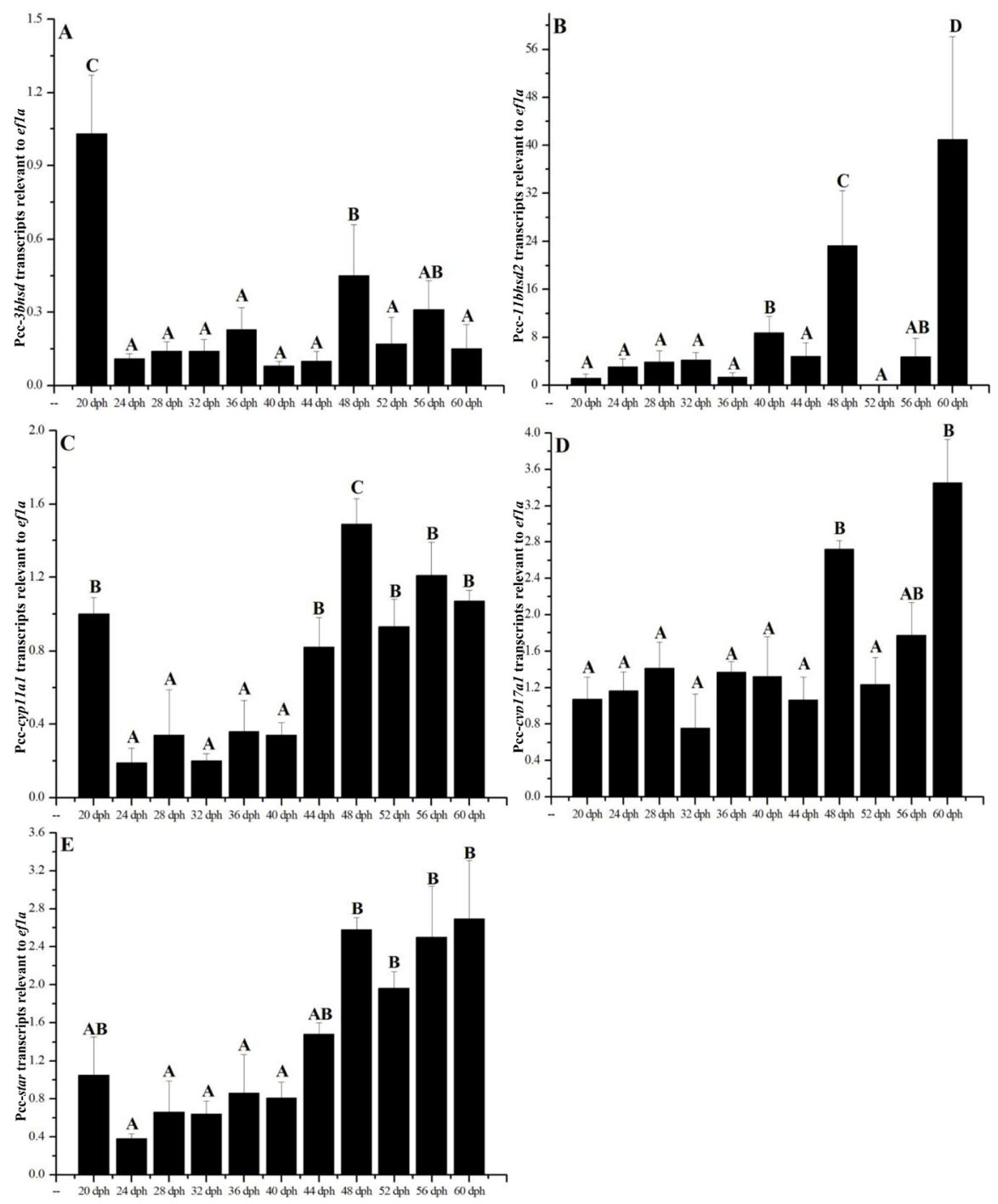

Figure 6. Temporal gene expression profiles of steroidogenic genes at 11 different developmental stages. A. Pcc3bhsd, B. Pcc-11bhsd, C. Pcc-cyp11a1, D. Pcc-cyp17a1, and E. Pcc-star. The different capital letters indicate highly significant differences $(P<0.05)$. 


\section{Temporal distributions of structural genes}

The transcript levels of Pcc-vtg $B$ exhibited significantly higher expression from 48 to 60 dph $(P<0.05$; Figure 7A) compared to levels measured from 24 to $44 \mathrm{dph}$. The transcript levels of Pcc-zp2 exhibited significantly higher expression from 44 to $60 \mathrm{dph}(\mathrm{P}<0.05$; Figure $7 \mathrm{~B})$ compared to levels measured from 20 to $44 \mathrm{dph}$.

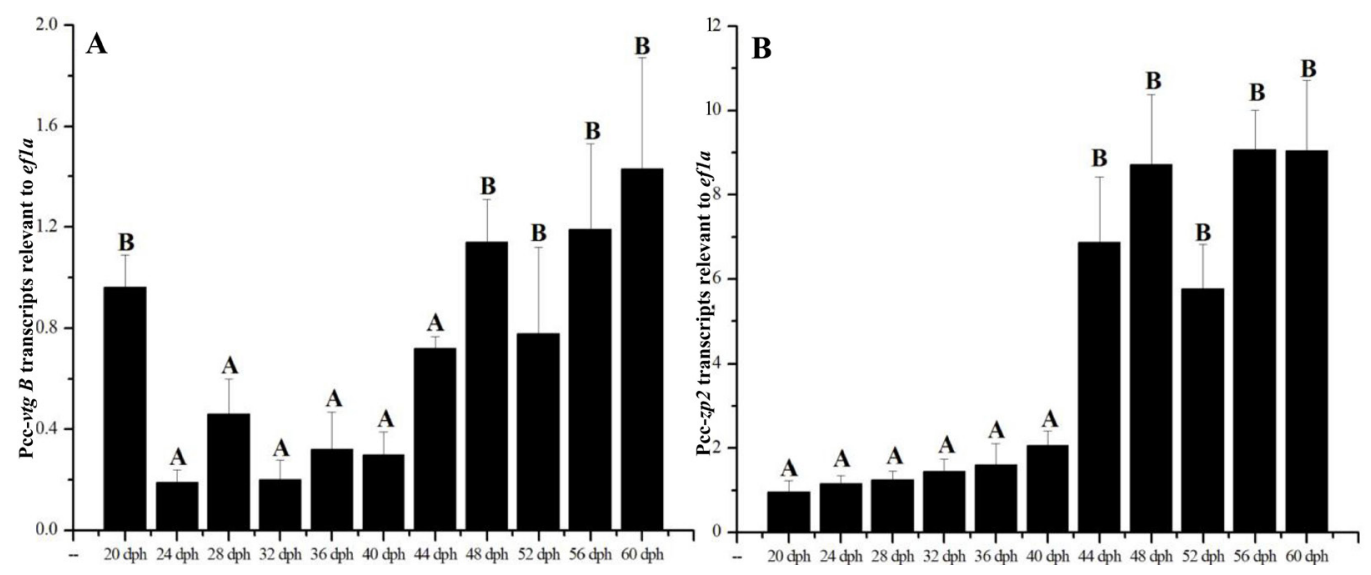

Figure 7. Temporal gene expression profiles of structural genes at 11 different developmental stages. A. Pcc-vtg $B$ and B. Pcc-zp2. The different capital letters indicate highly significant differences $(P<0.05)$.

\section{DISCUSSION}

\section{Tissue-specific distribution of the target genes}

Foxl2 is involved in the regulation of cholesterol and steroid metabolism, apoptosis, reactive oxygen species detoxification, and cell proliferation (Caburet et al., 2012). nr5a1 is expressed in various tissues, and its transcripts were higher in testes than in ovaries. The results of the present study indicated that Pcc-fox/2 and Pcc-nr5a $1 \mathrm{~b}$ transcripts in both eye and ovary tissues were significantly lower than those detected in other tissues. The actual function of Pcc-fox/2 and Pcc-nr5a1b in gynogenic fish was not determined in the current study. Recently, two subtypes of sox9 (sox9a/b) were found in zebrafish and medaka (Chiang et al., 2001), but reports of gene function in fish sox9a are scarce (Rodríguez-Marí et al., 2005). Higher levels of sox9 were detected in testes than in other tissues, and it could be found in ovary tissues. The present study showed that Pcc-sox9a transcripts were detected in most tissues, and levels were significantly higher in kidney, hepatopancreas, and intestine tissues. These results were similar to those observed in other teleosts, which demonstrated the vital role of sox9 in the development of kidney tissues vasa is a biomarker associated with germ cell origination, migration, and proliferation. Zebrafish vasa was maternal, and it was persistently expressed during embryonic development. The predominant expression of Pcc-vasa transcripts occurred in ovary tissues as compared to other tissues, which suggested the critical role of Pcc-vasa in gonadal development.

Steroidogenic genes were found in different tissues (e.g., 11 bhsd2 transcripts accumulated in tilapia testis and ovary), and these genes were also found in the testis, liver, kidney, 
and gill tissues of catfish (Rasheeda et al., 2010). cyp11b1 and cyp11a2 (homologs of cyp11a1 gene copies) played important roles in androgen synthesis (Parajes et al., 2013), and they are associated with sex differentiation in teleosts (Hsu et al., 2009; Evans and Nunez, 2010). Pcc$3 b h s d$ and Pcc-11bhsd2 transcript levels were significantly higher in brain than in other tissues. Expression levels of Pcc-cyp11a and Pcc-star in gill, intestine, and muscle tissues were just as high as those observed in kidney and ovary tissues. Moreover, Pcc-cyp11a1 and Pcc-star transcripts were significantly higher in hepatopancreas, muscle, and spleen tissues. cyp17a1 transcripts were found in gonads of medaka, tilapia, zebrafish, and barfin flounder (Jin et al., 2012), and transcripts were also found in brain and gonadal tissues of half-smooth tongue-sole (Chen et al., 2010) and in both kidney and gonad tissues of Korean rockfish (Mu et al., 2013). cyp17a1 was found to be a key factor associated with mature oocyte cells, and Pcc-cyp17a1 transcripts were only found in ovary, hepatopancreas, eye, and gill tissues in the present study, which demonstrated that steroidogenic genes were involved in gonadal development of gynogenic Pcc-zp, a female-specific gene associated with ovarian development, was present in ovary tissues before being transported to hepatopancreas tissue (Modig et al., 2006), which contains hepatic-specific and ovarian-specific expression patterns (Wu et al., 2012). Pcc-zp2 was highly significant in brain, hepatopancreas, kidney, ovary, and spleen tissues, and these results were the same as those reported in the rare minnow. Ovarian-specific zp2 was found in zebrafish, crucian carp, and goldfish (Mold et al., 2001; Shi et al., 2013), and $z p$ was found in both the hepatopancreas and ovary tissues of medaka and pufferfish (Kanamori et al., 2003). The results of the present study suggested that Pcc-zp2 is associated with the ovarian/hepatic-shared expression pattern.

\section{Time of sexual differentiation in gynogenic Pcc}

The sexual differentiation times of zebrafish, Clarias gariepinus, and gynogenic Pcc are 19, 30-40, and approximately $20 \mathrm{dph}$, respectively (Raghuveer et al., 2011). This information revealed the formation of early testes at $10 \mathrm{dph}$ in zebrafish (Jørgensen et al., 2008) and intratesticular efferent duct immersion at $25 \mathrm{dph}$ in tilapia (Kobayashi et al., 2008), which were checked via histological observation. With respect to the time of sexual differentiation for Pcc, it was difficult to define an accurate time without histological verification (even though we attempted to do so in the present study). However, steroidogenic genes were associated with the synthesis of endogenous E2, which guides sexual differentiation. The present study showed that the expression levels of steroidogenic genes (together with sex differentiation-related, steroid receptor, and structural genes), were significantly higher at 40 and/or $48 \mathrm{dph}$ than at other time points, with the exception of Pcc-vasa, Pcc-er alpha2, Pcc-esr2a, Pcc-3bhsd, and Pcc-11bhsd2. 3bhsd is associated with the conversion from pregnenolone into progesterone (Arukwe et al., 2008; Evans and Nunez, 2010). Moreover, it is predominantly expressed in the mitochondrion, which is active in the early developmental stages of fish. The amount of steroidogenic genes persistently increased from 44 to $60 \mathrm{dph}$, which suggested that steroidogenesis was active from $44 \mathrm{dph}$, and 40 and $48 \mathrm{dph}$ were two key time points based on our previous studies (Li et al., 2013a; Zheng et al., 2014).

\section{Temporal distribution of the target genes}

Some research focused on the gene expression profiles of gender-specific genes to discover the key time points of sexual differentiation in different teleosts (Rodríguez-Marí et al., 
2005; Jørgensen et al., 2008; Kobayashi et al., 2008). We collected the steroid receptor gene expression data reported in European seabass (Blázquez and Piferrer, 2005), fathead minnow (Filby and Tyler, 2005), goldfish (Nelson and Habibi, 2010), rainbow trout (Hale et al., 2011), rare minnow (Wang et al., 2011), and loach (Zhang et al., 2012), and we found that most steroid receptor genes reached the highest expression levels at different time points. The results of the present study showed that steroid receptor genes simultaneously peaked at $48 \mathrm{dph}$, and were associated with active steroidogenesis from 48 to $60 \mathrm{dph}$. Furthermore, we suggested that steroid receptor and steroidogenic genes were associated with the ovarian development of gynogenic Pcc, and that they were involved in the maintenance of endogenous steroid hormones.

Fish sex differentiation is oriented towards one of the sexes, and it is largely dependent on endogenous sex steroid hormone levels. Therefore, a change in the balance of steroid hormones can shift the differentiating pathway. A positive correlation exists between endogenous E2 and cyp19a1a gene expression in teleosts (Shanthanagouda et al., 2012). Some transcriptional factors (e.g., sex differentiation-related genes in the present study) were found to mediate endogenous E2 synthesis by directly or indirectly regulating cyp19a1a transcripts. sox $9 a$ and fox 12 were associated with the battle of sexes and the control of endogenous steroid hormone balance. Recently, cyp19a1a was found to be regulated by dmrt1 and its antagonistic gene, fox/2 (Li et al., 2013b), and fox/2 was confirmed as a cyp19a1a regulator. In the present study, the sex differentiation-related genes (Pcc-foxl2, nr5a1b, and sox9a) were significantly higher at 48 dph compared with other time points, which indicated that $48 \mathrm{dph}$ was the turning point. The other three genes (Pcc-amh, Pcc-dax1, and Pcc-cyp19a1a) were reported in our previous study (Li et al., 2013a), and the floating changes in these gene expression patterns may be due to different types of reproduction. For example, the diploid zebrafish represents a proterogynous fish that undergoes the conversion from the female to the male phenotype, while the triploid Pcc represents a gynogenic fish.

\section{Conflicts of interest}

The authors declare no conflict of interest.

\section{ACKNOWLEDGMENTS}

We thank Kamira Barry for providing grammar and spelling checks of the manuscript. Research supported by the Special Fund of Fundamental Scientific Research Business Expense for Central Public Research Institutes (\#2015JBFR03), the National Natural Science Foundation of China (\#31270547), the China Agriculture Research System (\#CARS-49), and the National Science and Technology Pillar Program (\#2015BAD13B03).

\section{REFERENCES}

Arukwe A, Nordtug T, Kortner TM, Mortensen AS, et al. (2008). Modulation of steroidogenesis and xenobiotic biotransformation responses in zebrafish (Danio rerio) exposed to water-soluble fraction of crude oil. Environ. Res. 107: 362-370. http:// dx.doi.org/10.1016/j.envres.2008.02.009

Blázquez M and Piferrer F (2005). Sea bass (Dicentrarchus labrax) androgen receptor: cDNA cloning, tissue-specific expression, and mRNA levels during early development and sex differentiation. Mol. Cell. Endocrinol. 237: 37-48. http:// dx.doi.org/10.1016/j.mce.2005.04.001

Caburet S, Georges A, L'Hôte D, Todeschini AL, et al. (2012). The transcription factor FOXL2: at the crossroads of ovarian physiology and pathology. Mol. Cell. Endocrinol. 356: 55-64. http://dx.doi.org/10.1016/j.mce.2011.06.019 
Chen CF, Wen HS, Wang ZP, He F, et al. (2010). Cloning and expression of P450c17-I (17 $\alpha$-hydroxylase/17,20-lyase) in brain and ovary during gonad development in Cynoglossus semilaevis. Fish Physiol. Biochem. 36: 1001-1012. http://dx.doi. org/10.1007/s10695-009-9378-7

Chiang EFL, Pai Cl, Wyatt M, Yan Y-L, et al. (2001). Two sox9 genes on duplicated zebrafish chromosomes: expression of similar transcription activators in distinct sites. Dev. Biol. 231: 149-163. http://dx.doi.org/10.1006/dbio.2000.0129

Evans AN and Nunez BS (2010). Regulation of mRNAs encoding the steroidogenic acute regulatory protein and cholesterol side-chain cleavage enzyme in the elasmobranch interrenal gland. Gen. Comp. Endocrinol. 168: 121-132. http://dx.doi. org/10.1016/j.ygcen.2010.04.018

Filby AL and Tyler CR (2005). Molecular characterization of estrogen receptors $1,2 \mathrm{a}$, and $2 \mathrm{~b}$ and their tissue and ontogenic expression profiles in fathead minnow (Pimephales promelas). Biol. Reprod. 73: 648-662. http://dx.doi.org/10.1095/ biolreprod.105.039701

Hale MC, Xu P, Scardina J, Wheeler PA, et al. (2011). Differential gene expression in male and female rainbow trout embryos prior to the onset of gross morphological differentiation of the gonads. BMC Genomics 12: 404. http://dx.doi. org/10.1186/1471-2164-12-404

Hsu HJ, Lin JC and Chung BC (2009). Zebrafish cyp11a1 and hsd3b genes: structure, expression and steroidogenic development during embryogenesis. Mol. Cell. Endocrinol. 312: 31-34. http://dx.doi.org/10.1016/j.mce.2009.07.030

ljiri S, Kaneko H, Kobayashi T, Wang DS, et al. (2008). Sexual dimorphic expression of genes in gonads during early differentiation of a teleost fish, the Nile tilapia Oreochromis niloticus. Biol. Reprod. 78: 333-341. http://dx.doi.org/10.1095/ biolreprod.107.064246

Jensen KM, Korte JJ, Kahl MD, Pasha MS, et al. (2001). Aspects of basic reproductive biology and endocrinology in the fathead minnow (Pimephales promelas). Comp. Biochem. Physiol. C Toxicol. Pharmacol. 128: 127-141.

Jin GX, Wen HS, He F, Li JF, et al. (2012). Molecular cloning, characterization expression of P450c17-I and P450c17-II and their functions analysis during the reproductive cycle in males of barfin flounder (Verasper moseri). Fish Physiol. Biochem. 38: 807-817. http://dx.doi.org/10.1007/s10695-011-9564-2

Jobling S, Nolan M, Tyler CR, Brighty G, et al. (1998). Widespread sexual disruption in wild fish. Environ. Sci. Technol. 32: 2498-2506. http://dx.doi.org/10.1021/es9710870

Jørgensen A, Morthorst JE, Andersen O, Rasmussen LJ, et al. (2008). Expression profiles for six zebrafish genes during gonadal sex differentiation. Reprod. Biol. Endocrinol. 6: 25. http://dx.doi.org/10.1186/1477-7827-6-25

Kanamori A, Naruse K, Mitani H, Shima A, et al. (2003). Genomic organization of ZP domain containing egg envelope genes in medaka (Oryzias latipes). Gene 305: 35-45. http://dx.doi.org/10.1016/S0378-1119(02)01211-8

Kobayashi T, Kajiura-Kobayashi H, Guan G and Nagahama Y (2008). Sexual dimorphic expression of DMRT1 and Sox9a during gonadal differentiation and hormone-induced sex reversal in the teleost fish Nile tilapia (Oreochromis niloticus). Dev. Dyn. 237: 297-306. http://dx.doi.org/10.1002/dvdy.21409

Li M, Wang L, Wang H, Liang H, et al. (2013a). Molecular cloning and characterization of amh, dax1 and cyp19a1a genes in pengze crucian carp and their expression patterns after $17 \alpha$-methyltestosterone exposure in juveniles. Comp. Biochem. Physiol. C Toxicol. Pharmacol. 157: 372-381.

Li MH, Yang HH, Li MR, Sun YL, et al. (2013b). Antagonistic roles of Dmrt1 and Fox/2 in sex differentiation via estrogen production in tilapia as demonstrated by TALENs. Endocrinology 154: 4814-4825. http://dx.doi.org/10.1210/en.2013-1451

Livak KJ and Schmittgen TD (2001). Analysis of relative gene expression data using real-time quantitative PCR and the 2(-Delta Delta C(T)) Method. Methods 25: 402-408. http://dx.doi.org/10.1006/meth.2001.1262

Modig C, Modesto T, Canario A, Cerdà J, et al. (2006). Molecular characterization and expression pattern of zona pellucida proteins in gilthead seabream (Sparus aurata). Biol. Reprod. 75: 717-725. http://dx.doi.org/10.1095/biolreprod.106.050757

Mold DE, Kim IF, Tsai CM, Lee D, et al. (2001). Cluster of genes encoding the major egg envelope protein of zebrafish. Mol. Reprod. Dev. 58: 4-14. http://dx.doi.org/10.1002/1098-2795(200101)58:1<4::AID-MRD2>3.0.CO:2-P

Mu WJ, Wen HS, He F, Li JF, et al. (2013). Cloning and expression analysis of the cytochrome P450c17s enzymes during the reproductive cycle in ovoviviparous Korean rockfish (Sebastes schlegeli). Gene 512: 444-449. http://dx.doi.org/10.1016/j. gene.2012.10.064

Nelson ER and Habibi HR (2010). Functional significance of nuclear estrogen receptor subtypes in the liver of goldfish. Endocrinology 151: 1668-1676. http://dx.doi.org/10.1210/en.2009-1447

Parajes S, Griffin A, Taylor AE, Rose IT, et al. (2013). Redefining the initiation and maintenance of zebrafish interrenal steroidogenesis by characterizing the key enzyme cyp11a2. Endocrinology 154: 2702-2711. http://dx.doi.org/10.1210/ en.2013-1145

Raghuveer K, Senthilkumaran B, Sudhakumari CC, Sridevi P, et al. (2011). Dimorphic expression of various transcription factor and steroidogenic enzyme genes during gonadal ontogeny in the air-breathing catfish, Clarias gariepinus. Sex Dev. 5: 213-223. http://dx.doi.org/10.1159/000328823 
Rasheeda MK, Kagawa H, Kirubagaran R, Dutta-Gupta A, et al. (2010). Cloning, expression and enzyme activity analysis of testicular 11 $\beta$-hydroxysteroid dehydrogenase during seasonal cycle and after hCG induction in air-breathing catfish Clarias gariepinus. J. Steroid Biochem. Mol. Biol. 120: 1-10. http://dx.doi.org/10.1016/j.jsbmb.2010.02.014

Rodríguez-Marí A, Yan YL, Bremiller RA, Wilson C, et al. (2005). Characterization and expression pattern of zebrafish AntiMüllerian hormone $(A m h)$ relative to sox9a, sox9b, and cyp19a1a, during gonad development. Gene Expr. Patterns 5: 655-667. http://dx.doi.org/10.1016/j.modgep.2005.02.008

Sampath Kumar R, ljiri S and Trant JM (2000). Changes in the expression of genes encoding steroidogenic enzymes in the channel catfish (Ictalurus punctatus) ovary throughout a reproductive cycle. Biol. Reprod. 63: 1676-1682. http://dx.doi. org/10.1095/biolreprod63.6.1676

Segner H, Casanova-Nakayama A, Kase R and Tyler CR (2013). Impact of environmental estrogens on Yfish considering the diversity of estrogen signaling. Gen. Comp. Endocrinol. 191: 190-201. http://dx.doi.org/10.1016/j.ygcen.2013.05.015

Shanthanagouda AH, Patil JG and Nugegoda D (2012). Ontogenic and sexually dimorphic expression of cyp19 isoforms in the rainbowfish, Melanotaenia fluviatilis (Castelnau 1878). Comp. Biochem. Physiol. A Mol. Integr. Physiol. 161: $250-258$. http://dx.doi.org/10.1016/j.cbpa.2011.11.006

Shi JW, Sheng JQ, Peng K, Wang JH, et al. (2013). Expression pattern of the zona pellucida 3 (ZP3) gene during ovarian development and the location of ZP3 protein in oocytes in a natural, wild triploid crucian carp mutant, Carassius auratus var. Pingxiangnensis. Genet. Mol. Res. 12: 5640-5650. http://dx.doi.org/10.4238/2013.November.18.13

von Hofsten J, Larsson A and Olsson PE (2005). Novel steroidogenic factor-1 homolog (ff1d) is coexpressed with anti-Mullerian hormone $(A M H)$ in zebrafish. Dev. Dyn. 233: 595-604. http://dx.doi.org/10.1002/dvdy.20335

Wang H, Wang J, Wu T, Qin F, et al. (2011). Molecular characterization of estrogen receptor genes in Gobiocypris rarus and their expression upon endocrine disrupting chemicals exposure in juveniles. Aquat. Toxicol. 101: 276-287. http://dx.doi. org/10.1016/j.aquatox.2010.10.009

Wang YS and Lou SW (2006). Structural and expression analysis of hepatic vitellogenin gene during ovarian maturation in Anguilla japonica. J. Steroid Biochem. Mol. Biol. 100: 193-201. http://dx.doi.org/10.1016/j.jsbmb.2006.04.011

Wu GC, Tomy S, Lee MF, Lee YH, et al. (2010). Sex differentiation and sex change in the protandrous black porgy, Acanthopagrus schlegeli. Gen. Comp. Endocrinol. 167: 417-421. http://dx.doi.org/10.1016/j.ygcen.2009.11.003

Wu T, Wang H, Qin F, Liu S, et al. (2012). Expression of zona pellucida B proteins in juvenile rare minnow (Gobiocypris rarus) exposed to $17 \alpha$-ethinylestradiol, 4-nonylphenol and bisphenol A. Comp. Biochem. Physiol. C Toxicol. Pharmacol. 155: 259-268.

Zhang Y, Wang H, Qin F, Liu S, et al. (2012). Molecular characterization of estrogen receptor genes in loach Paramisgurnus dabryanus and their expression upon 17 $\alpha$-ethinylestradiol exposure in juveniles. Gen. Comp. Endocrinol. 178: $194-205$. http://dx.doi.org/10.1016/j.ygcen.2012.06.004

Zheng Y, Wang L, Li M, Liang H, et al. (2013). Molecular characterization of five steroid receptors from pengze crucian carp and their expression profiles of juveniles in response to $17 \alpha$-ethinylestradiol and $17 \alpha$-methyltestosterone. Gen. Comp. Endocrinol. 191: 113-122. http://dx.doi.org/10.1016/j.ygcen.2013.06.011

Zheng Y, Liang H, Xu P, Li M, et al. (2014). Molecular cloning of Pcc-dmrt1s and their specific expression patterns in Pengze crucian carp (Carassius auratus var. Pengze) affected by $17 \alpha$-methyltestosterone. Fish Physiol. Biochem. 40: 1141-1155.

Zhou L and Gui JF (2010). Molecular mechanisms underlying sex change in hermaphroditic groupers. Fish Physiol. Biochem. 36: 181-193. http://dx.doi.org/10.1007/s10695-008-9219-0 